\title{
Partnering for workplace health and safety
}

\author{
Verna Blewett $\mathrm{t}^{\mathrm{a},{ }^{*}}$ and Jill Dorrian ${ }^{\mathrm{b}}$ \\ a Appleton Institute, Central Queensland University, 44 Greenhill Rd, Wayville, South Australia 5034, Australia \\ ${ }^{\mathrm{b}}$ School of Psychology, University of South Australia, GPO Box 2447, Adelaide, South Australia 5001, Australia
}

\begin{abstract}
Worker involvement in decision-making about the workplace can improve safety, health, productivity and the quality of organizational outputs. Australian work health and safety (WHS) legislation mandates worker involvement and gives elected Health and Safety Representatives (HSRs) specific powers, but there has been limited research about the impact of that regulatory framework on the nature, quality and outcomes of worker involvement. As part of a wider review of worker representation in WHS, we investigated the role and impact (positive and negative) of elected HSRs on WHS] in South Australia using a newly-constructed survey instrument. This paper reports on the development of the instrument and the initial findings of the research. The initial survey dimensions and items were developed from earlier research on consultation in South Australia and were refined and validated through this research. The survey has 9 constructs and 61 items and has both face validity and high internal consistency. This research is a step forward for researchers and policy makers seeking a means of determining the effectiveness of worker participation in WHS. It provides an instrument, pilot baseline data and a method that could be used internationally to enable this assessment.
\end{abstract}

Keywords: workforce participation, participation survey, multi-method research, health and safety representatives

\section{Introduction}

Worker participation in decision-making is a way of improving the sense of control and autonomy at work [6]; of reducing alienation and creating a sense of 'democracy' at work [3]. Organizations have much to gain from worker involvement in decisionmaking about the workplace because it can improve safety, health, productivity and quality of organizational outputs.

Each Australian jurisdiction's work health and safety legislation mandates worker involvement in some form. South Australian workplace health and safety legislation, the Occupational Health, Safety and Welfare Act, 1986, does this through the election of worker representatives (health and safety representatives - HSRs) who are given specific rights and powers. Their rights cover the capacity to represent their work group on health and safety matters, while their powers include the capacity to stop unsafe work by applying a 'default notice' that is legally binding on the organization. The nationally harmonized Work Health and Safety Act, which at the time of writing is proposed to be introduced in January 2012, also con- tains specific provisions for elected HSRs similar to those currently in place in South Australia.

Despite the existence of these regulatory provisions there has been limited research about the impact of the regulatory framework on the nature, quality and outcomes of worker involvement in work health and safety (WHS).

The context of this research was an evaluation of the South Australian government-funded Partnership Programme that provided support to 12 unions to develop and implement strategies to increase the number of HSRs in Priority Industries in order to better manage Priority Risks and improve workplace health and safety in South Australia. The priority industries (construction; transport and storage; manufacturing; community services; agriculture, forestry and fishing; wholesale and retail trade; recreation, personal and other services; and finance, property and business services) are known to contribute the largest share of workers' compensation claims in the state, especially because of their exposure to the priority risks (body stressing, slips, trips and falls, being hit by moving objects, hitting objects with a part of the body).

\footnotetext{
* Corresponding author: Associate Professor Verna Blewett. E-mail: v.blewett@cqu.edu.au
} 
The unions were: the Australian Manufacturing Workers' Union (AMWU), the Australasian Meat Industry Employees' Union (AMIEU), the Australian Services Union (ASU), the Australian Workers Union (AWU), the Communications, Electrical, Electronics, Plumbing and Allied Services Union (CEPU), the Construction, Forestry, Mining and Engineering Union (CFMEU - Construction), the Independent Education Union (IEU) the National Union of Workers (NUW), the Shop Distributors Union (SDA) the Textile, Clothing and Footwear Union of Australia (TCFUA) the Transport Workers Union (TWU), and United Voice (UV) (formerly the Liquor Hospitality and Miscellaneous Union (LHMU)). Each union used different strategies to achieve its objectives and these are the subject of our report [2].

In conducting this evaluation, we investigated the role and impact (positive and negative) of elected HSRs on work health and safety in South Australia using a newly-constructed survey instrument. This paper reports on the development of the instrument and the preliminary findings of the research.

\section{Method}

\subsection{Dimensions of the HSR Survey}

A principal tool in this research is the HSR Questionnaire that has been developed to provide quantitative analysis of HSR's experience, and perceptions of HSRs in the workplace. Despite their limitations, surveys remain "a remarkably useful and efficient tool for learning about people's opinions and behaviors" [5].

The 17 draft dimensions used in the questionnaire, as listed in Table 1, were derived from Working Together, earlier research into worker participation and involvement in decision-making on OHS in South Australia [1] with reference to the literature [4,5]. Although the questionnaire was lengthy, with 79 perception items, we considered that there was value in extending the coverage in this first version of the questionnaire to give maximum opportunity to use factor analysis to either confirm the draft dimensions, or determine new dimensions. The questionnaire also included a free-text section for additional comments. Data from this section were analyzed with the qualitative data. Matched versions of the questionnaire were also produced for fellow workers and OHS Professionals and Managers to complete. Both hard copy and on-line versions were produced.
Table 1

List of initial dimensions in the HSR questionnaire

\begin{tabular}{ll}
\hline 1. & About HSRs and the Partnership Program \\
\hline 2. & Sincerity in consultation \\
\hline 3. & Respectful relationships \\
\hline 4. & Understanding who's responsible for what \\
\hline 5. & Building OHS culture \\
\hline 6. & The perception that OHSW cannot be ignored \\
\hline 7. & Internal and external influences on senior management \\
\hline 8. & Effective and relevant training \\
\hline 9. & Training of employees in OHS \\
& (not including HSR training) \\
\hline 10. & Maintaining interest in being an HSR \\
\hline 11. & Availability of information \\
\hline 12. & Mentoring \\
\hline 13. & The HSR role \\
\hline 14. & Support for HSRs in the workplace \\
\hline 15. & HSRs as leaders \\
\hline 16. & HSRs' knowledge and abilities \\
\hline 17. & Notifiable Incidents \\
\hline
\end{tabular}

\subsection{Finding HSRs}

In South Australia HSRs are required to be registered with the regulator, SafeWork SA. The database of HSRs is called the HSR Register and is unique in Australia as no other jurisdiction has this registration requirement. At the time of the research the HSR Register held 6,555 HSR records. Unfortunately there have been ongoing difficulties with the maintenance of the HSR Register; its accuracy is unknown and it is difficult to interrogate. However, it was the only database of HSRs available to the researchers.

\subsection{User-testing the survey}

The draft surveys were user-tested by eight HSRs, four people who were managers/OHS professionals and five workers. User testing showed that organising the material to hand to others in the workplace (managers/OHS professionals or workers) as colourcoded packs would make the instructions clearer. Minor wording changes were suggested to questions where there was some ambiguity or the question was difficult to understand. Users

Interestingly, one user did not understand the term 'lip service' in the item "Our managers pay lip ser- 
vice to OHS". On considering this feedback the decision was taken to include the question in any case, considering that the term was in common usage. However, this question was one of a small group of questions that was not answered by more than $20 \%$ of respondents and was subsequently left out of the data analysis inferring that many people may not understand the term. This reinforced how important the process of user testing is to the quality of documents and how necessary it is to heed the advice of users.

\subsection{Administering the survey}

To boost the response rate HSRs were given advanced information about the research in an initial letter that was sent by SafeWork SA to all HSRs on the HSR Register, either by postal letter or email, six weeks prior to the opening of the survey. The HSR Questionnaire was sent by SafeWork SA (to protect privacy) to all HSRs on the HSR Register either in hard copy or as a url in an email. Each HSR was asked to forward the email or hand hard copies of the questionnaire to an OHS professional or manager, and a fellow worker in their organization. Reply paid envelopes addressed to the principal researcher were provided to facilitate return of the questionnaires.

\subsection{Focus groups and interviews}

Seven focus groups were held with HSRs in Adelaide and regional centres in South Australia. The focus groups covered discussion about their experiences, expectations, the perceived efficacy of their role, how they perform their role, and what they need to perform their role effectively. These were run in conjunction with a series of briefing sessions for HSRs conducted by SafeWork SA to ensure the widest range of industries, firms and geographic location were represented in the research. A total of 44 HSRs participated in the focus groups. Interviews were conducted with 29 individuals from the participating unions and representatives of labor and industry associations.

\section{Findings}

It is not known how many HSR Questionnaires reached HSRs and there was no means of determining this. However, it is acknowledged that the re- sponse rate was very small. Nonetheless there were sufficient returns to enable statistical analysis.

Overall, there was approximately $3 \%$ of the 79 "Consultation in the Workplace" and "Workplace experience" items to which participants did not respond. In order to avoid imbalance caused by individuals only appearing in the analysis for few questions, those who failed to respond to more than $20 \%$ of these items ( $>15 / 79$ missing) were excluded from the analyses. Fourteen individuals met this criterion, leaving a dataset of $n=200$ for further analysis.

\subsection{Factor analysis}

A factor analysis was conducted with Principle Axis Factoring and Promax rotation. Consistent with standard practice, a minimum factor loading of 0.4 was specified. The analysis was an iterative process where items that did not load onto any factors, or that were the sole item loading onto a single factor, were removed. A preliminary model produced seven factors and explained $56 \%$ of the variance. The seventh factor only contained two items, and when internal consistencies for the seven factors were tested using Cronbach's alpha, the seventh factor yielded an alpha value well below the acceptable level of 0.70 . This factor was removed, and a final model contained six factors. Internal consistency figures are in brackets:

- Management Attitude and Action (0.9)

- Training and Induction (0.9)

- Appreciation and Value of HSRs (0.8)

- Support for HSRs (0.8)

- Characteristics of HSRs (0.8)

- OHS Understanding (0.8)

A second factor analysis was conducted to classify the items that were directed at HSRs only. This was done using the same specifications and process as outlined above. The final model produced three factors with internal consistency figures in brackets:

HSR Encouragement and Appreciation (0.9)

HSR Having a Voice (0.8)

HSR Competence and Commitment (0.7)

Overall, these factors have high factor loadings and internal consistency, which demonstrates a strong fit for this particular dataset $(n=200)$. Further analysis suggest that these factors are sensitive to demographic differences as well as differences between HSRs, Managers and Workers, which provides further support for this factor structure. However, it should be noted that results may be different in a 
larger, or more diverse sample. Therefore, although these are promising pilot results for design of such a questionnaire, the next step would be to collect another larger dataset, and investigate whether this factor structure holds in the new sample.

\section{Conclusion}

This research is a step forward for researchers and policy makers seeking a means of determining the importance of participation and consultation in workplace health and safety. This research provides and instrument, pilot baseline data and a method that could be used nationally. This is particularly timely given the forthcoming introduction of harmonised workplace health and safety legislation in Australia and the future need to evaluate its impact

\section{Acknowledgements}

Thanks to: SafeWork SA for the initial funding of this project under the Small Grants Scheme; to Safe Work Australia for supplementing the funding; to the Project Steering Committee for sagacious advice; to
Harrison Research Pty Ltd for on-line hosting and data entry; to survey participants, attendees at focus groups and the representatives of the unions, industry and SafeWork SA who agreed to be interviewed.

\section{References}

[1] V. Blewett, Working together: a review of the effectiveness of the health and safety representative and workplace health and safety committee system in South Australia. Adelaide, WorkCover Corporation (2001)

[2] V.Blewett, and J. Dorrian, Partnering for OHS. Volume 2: Worker participation in work health and safety. Adelaide, SafeWork SA (2011).

[3] O. Busck, H. Knudsen, et al., The transformation of employee participation: Consequences for the work environment. Economic and Industrial Democracy 31 (2010): 285-305.

[4] E. D. de Leeuw, J. J. Hox, et al, International handbook of survey methodology. New York, Psychology Press (2008).

[5] Dillman, D. A., J. D. Smyth, et al., Internet, mail and mixedmode surveys: the tailored design method. New York, John Wiley \& Sons (2009).

[6] Karasek, R., Job demands, job decision latitude and mental strain: Implications for job redesign. Administrative Science Quarterly 24(1979): 285-307. 